BULLETIN Bulletin hispanique

HISPANIQUE Université Michel de Montaigne Bordeaux

$122-2 \mid 2020$

L'épithalame en Espagne

\title{
Francesc J. Hernàndez i Dobon, Juan Luis Vives, Un gran humanista
}

Valencia: Editorial Sargantana

Pedro Fernández Requena

\section{OpenEdition}

Journals

Edición electrónica

URL: http://journals.openedition.org/bulletinhispanique/11872

DOI: 10.4000/bulletinhispanique. 11872

ISBN: 1775-3821

ISSN: $1775-3821$

\section{Editor}

Presses universitaires de Bordeaux

\section{Edición impresa}

Fecha de publicación: 20 diciembre 2020

Paginación: 757-762

ISBN: 979-10-300-0606-3

ISSN: 0007-4640

\section{Referencia electrónica}

Pedro Fernández Requena, «Francesc J. Hernàndez i Dobon, Juan Luis Vives, Un gran humanista», Bulletin hispanique [En línea], 122-2 | 2020, Publicado el 14 diciembre 2020, consultado el 19 enero 2021. URL: http://journals.openedition.org/bulletinhispanique/11872 ; DOI: https://doi.org/10.4000/ bulletinhispanique.11872

Este documento fue generado automáticamente el 19 enero 2021.

Tous droits réservés 


\section{Francesc J. Hernàndez i Dobon, Juan Luis Vives, Un gran humanista}

Valencia: Editorial Sargantana

Pedro Fernández Requena

\section{REFERENCIA}

Francesc J. Hernàndez i Dobon, Juan Luis Vives, Un gran humanista, Valencia: Editorial Sargantana, 2019, 117 p. - ISBN: 978-84-17731-02-1

1 Muchos han sido los investigadores que han incluido, en alguna de sus contribuciones, un estudio sobre la vida y obra de Juan Luis Vives. Se podría citar la labor de Gregorio Mayans i Ciscar, cuya edición de los tratados del humanista -Opera omnia ${ }^{1}$ - va precedida, en su primer tomo, de una biografía pormenorizada² (p. 41-260). Otro gran académico, interesado en el valenciano, fue Carlos Noreña, que publicó en inglés un análisis ${ }^{3}$ muy exhaustivo sobre el devenir vital y literario de nuestro intelectual. Por último, cabría mencionar la pesquisa de Valentín Moreno Gallego; su libro ${ }^{4}$ nos presenta «un prototipo de personaje que vivió y sufrió las contradicciones de su etapa histórica y abarcó en sus escritos todos los campos del saber» (p. 13-14).

2 En esta misma línea, conviene referirse a la aportación de Francesc J. Hernàndez i Dobon, profesor adscrito a la Facultat de Ciències Socials de la Universitat de València. Su obra -titulada Juan Luis Vives. Un gran humanista- salió a la venta el 5 de septiembre de 2019. Dicha publicación corrió a cargo de la editorial Sargantana, que la incorporó en su colección de «personajes ilustres». Ésta tiene como objetivo poner a disposición de un lector no necesariamente especializado las biografías de un conjunto de eruditos. Menciónese -entre otras- la del novelista Benito Pérez Galdós o la del abogado y poeta valenciano Rafael Ferrer i Bigné; ambas fueron publicadas en 2019. En este volumen, Hernàndez i Dobon reúne un total de doce textos en versión castellana, extraídos de los principales tratados de Vives; éstos sirven para ilustrar ciertos momentos de la vida del 
polígrafo humanista. Así pues, el libro está formado por tres grandes apartados: capítulos biográficos, textos y bibliografía.

3 Esta publicación carece de unas páginas iniciales en que se expongan unas consideraciones previas. No obstante, se sabe que el trabajo de Francesc J. Hernàndez posee una larga trayectoria. Todo comenzó

hace diez años cuando la editorial Carena publicó en 2014 su edición comentada del diálogo 22 del Linguae latinae exercitatio (Brujas, 1538). Años después, Vicent Andreu, director del Institut Confuci de la Universitat de València, le propuso la elaboración de un libro para introducir al público chino en la figura de Juan Luis Vives. El resultado fue una aportación muy didáctica que contenía una selección de textos; con todo, dicho propósito no fructificó. Finalmente, cuando la editorial Sargantana inició su colección de personajes ilustres, le comunicó la idea de incluir la vida y obra del humanista valenciano; ello le permitió retomar el proyecto ${ }^{5}$.

En concreto, el grueso de esta contribución lo forman las partes dedicadas a los capítulos y a la antología de textos (p. 9-101). Para su recensión, se ha tomado como referencia biográfica el artículo ${ }^{6}$ de Ángel Gómez-Hortigüela. A modo de síntesis, podría decirse que una de las clasificaciones más idóneas sería la siguiente:

1. Orígenes familiares

2. Vives en París

3. Vives en los Países Bajos

4. Vives en Inglaterra

5. Regreso a Brujas

6. Últimos años

5 La primera categoría (p. 9-12) repara en la infancia y adolescencia del humanista. Francesc afirma (p. 10-11) que «nació en 1492, o 1493, en el seno de una familia de judíos conversos (...). Hacia 1507, empezó sus estudios en la Universitat de València». Para dilucidar este acontecimiento, se cita un pasaje (p. 59-60) de su Virginis Dei-Parentis Ovatio (París, 1514). En él se describe la entrada y el claustro del Estudi-General. Asimismo, el profesor Hernàndez ubica estos años en su contexto político y social: se creó la Inquisición, «cuyo objetivo era vigilar la autenticidad de todas las conversiones al cristianismo» (p. 8). En este sentido, la familia de Vives fue el punto de mira de las autoridades eclesiásticas; en consecuencia, «sus tíos fueron condenados a la hoguera en 1501» (p. 11).

6 En el segundo apartado que comprende el capítulo 2 (p. 13-16), el valenciano reside en París, donde «finalizó sus estudios en la Sorbona y publicó sus primeras obras en 1514» (p. 13); éstas fueron -según José Peña González (p. 14-15)- «Veritas Fucata, Christi Iesu triumphus y la Ovatio Virginis Dei Parentis». Según Hernàndez i Dobon (p.14), estos escritos «ponen de manifiesto el poder limitado de los gobernantes, que precisan de consejeros. Para este fin, los humanistas son los más indicados, pues conocen los saberes de la antigüedad clásica».

7 La tercera categoría, formada por los capítulos 3, 4 y 5 (p. 17-26), aborda las estancias de Vives en las principales ciudades de los Países Bajos: Brujas -desde «donde viajaba frecuentemente a la corte del rey Carlos de Habsburgo en Bruselas» (p. 17)- y Lovaina, «en cuya universidad dio clases y compuso algunos tratados» (p. 18). Prueba de ello sería el texto 2 (p. 31-62), extraído de su De initiis, sectis et laudibus philosophiae (Lovaina, 1518); en éste se exponen los beneficios de la filosofía: «llegar al principio indivisible del mundo para vivir alegres y felices con una norma de bien...» (p. 61). Por otro lado, 
no menos importante fue la relación del valenciano con otros eruditos: «Tomás Moro, Guillaume Budé o Erardo de la Marca, al que dirigió un elogio ${ }^{8}$ de Valencia en 1520» (p. 20). Además, cabe mencionar su amistad con Erasmo de Rotterdam, que «encomió la sabiduría de Vives en una carta ${ }^{9}$ dirigida a Juan de Parra; es más, encargó al humanista unas glosas a la Ciudad de Dios de San Agustín, publicadas en Lovaina en 1522» (p. 20-21). Según Hernàndez i Dobon, este comentario «fue su obra más importante hasta el momento, coincidiendo con una serie de malas noticias para Vives: el proceso inquisitorial contra su padre, el fallecimiento de su hermano Jaime y de Guillaume de Croÿ, su protector, las hostilidades eclesiásticas contra las ideas de Erasmo, etc.» (p. 23-25). Dichas tribulaciones fueron expuestas al jurista Cranevelt en varias misivas con fecha de 1523; éstas corresponden al texto 5 de la presente edición (p. 67-68).

8 La cuarta sección -conformada por los capítulos 6, 7 y 8 (p. 27-38)- empieza con un Vives enfrascado en la composición del De institutione feminae Christianae (Lovaina, 1523), dedicado a la reina consorte de Inglaterra Catalina de Aragón. En esta obra, el humanista considera que «también la mujer ha de formarse» (p. 27); así lo expresa: «aetate, qua videbitur iam idonea litteris et cognitioni rerum, incipiat ea discere quae ad cultum animi, quaeque ad tuendam regendamque domum spectant» (Mayans, 1790: t. iv, 73). Tras finalizar este tratado, el valenciano entró en la corte de Enrique viii, donde halló un panorama desolador: «el monarca inglés mantenía relaciones con las hermanas Anne y Mary Boleyn; esto provocó un enfrentamiento con el papa Julio ii y el consiguiente cisma de la iglesia anglicana. Vives, por su parte, apoyó a la reina, por lo que tuvo que abandonar Inglaterra en 1528» (p. 28-29).

9 En los dos capítulos sucesivos (p. 31-38), se reflejan aquellas obras redactadas durante su residencia en Londres. Una de ellas sería su Introductio ad sapientiam (Brujas, 1524), cuyo fragmento citado corresponde al texto 6 y expone el verdadero propósito de la sabiduría: «proporcionar una alegre serenidad de espíritu y apaciguar las pasiones» (p. 69-76). A continuación, se muestra un Vives comprometido con la quietud en contraposición al conflicto armado. Así pues, para favorecer la paz, envió varias cartas «al papa Adriano vi, a Enrique viii y al obispo de Lincoln» (p. 35). De este último, se propone la lectura de una misiva con fecha de 8 de julio de 1524, en la que el polígrafo humanista define la guerra como «la más depravada de las opiniones» (p. 77); se trata del texto 7 (p. 77-78). Por otra parte, en el texto 8 de la compilación -extraído de su $D e$ concordia et discordia in humano genere (Brujas, 1529)-, se defiende un estado «que vele por la paz» (p.79-81). Por último, era ejemplar la preocupación de Vives por el bienestar en las principales ciudades europeas. Esta actitud le llevó a plantear «argumentos morales y teológicos» (p.36) en su De subventione pauperum (Brujas, 1526). Para ilustrar la inquietud del humanista por la mendicidad en Brujas ${ }^{10}$, Francesc sugiere el texto 9; en él se recomiendan medidas para socorrer a pobres y convalecientes: «asegurar su alimentación, darles una ocupación para que no estén ociosos, separar a los enfermos del resto, etc.» (p. 83-90).

10 La quinta categoría relata la actividad intelectual de Vives posterior a su estancia en Inglaterra (p. 39-44) ${ }^{11}$. En primer lugar, se tiene en consideración su De disciplinis (Amberes, 1531), obra que dedicó a Juan iii de Portugal. En ésta se explican «las causas de la degradación de las ciencias, a saber las calamidades de las guerras, las malas praxis académicas, etc.» (p. 40). Todo esto aparece referenciado en el texto 10, pues «los saberes implican un comportamiento piadoso; a él se someten niños y emperadores» (p. 91-95). Acto seguido, el humanista finalizó, hacia 1535, su De Veritate Fidei Christianae, 
«no publicado en un principio por los conflictos religiosos y aparecido póstumamente en 1543 gracias a su amigo Cranevelt» (p. 42). Como ejemplo, puede leerse en el texto 11 una conversación entre un cristiano y un judío, que debaten la posibilidad de «someter la razón divina a la disciplina del saber» (p. 97-98).

11 Los capítulos 10 y 11 (p. 45-53) concluyen la biografía del valenciano con «una Europa azotada por las guerras, con una Iglesia incapaz de generar concordia y con un Vives que, pese a su salud enfermiza, se instaló en Breda como preceptor de Mencía de Mendoza» (p. 45-46). Durante su estancia, compuso su Linguae Latinae Exercitatio (Brujas, 1538). En esta obra, se proponen unos diálogos de dificultad creciente para el aprendizaje del latín; uno de ellos sería el 22, correspondiente al texto 12 del compendio (p. 99-101). En éste el polígrafo humanista describe para Mencía la ciudad del Turia, «ya que pronto se convertiría en virreina del Reino de Valencia» (p. 47). Cuando Vives abandonó Breda, regresó a Brujas; «allí vivió sus últimos días y falleció el 6 de mayo de 1540» (p. 50).

12 En las últimas páginas (p.105-107), el autor del libro incluye una relación de las ediciones más importantes de las obras de Vives. Por tanto, se hace alusión a la ya referida Opera omnia de Gregorio Mayans, así como a las contribuciones de Ismael Roca Meliá $^{12}$, José Jiménez Delgado ${ }^{13}$ o Lorenzo Riber ${ }^{14}$, cuyas traducciones en español han nutrido algunas citas de esta antología. De igual manera, no se pasan por alto unas recomendaciones (p. 106-107) para que el lector pueda adentrarse en los escritos del humanista. Un ejemplo de sugerencia serían los números de la revista Vivesiana ${ }^{15}$, que publica en abierto trabajos sobre Vives y su época.

13 Si bien hubiese sido, quizá, más práctico ubicar las referencias inmediatamente después de cada capítulo, y no al final en otro apartado -pues, de este modo, el lector podría indagar mejor en las vicisitudes de la biografía del valenciano-, ello no desmerece, en modo alguno, la labor realizada por Francesc J. Hernàndez en su libro. En efecto, el autor no ha descuidado momentos tan significativos de su vida como los continuos problemas con las autoridades inquisitoriales; este hecho explicaría, probablemente, «su huida a Francia en 1509» (Escudero, 2009: 14) ${ }^{16}$ o su decisión de «no ocupar la cátedra de retórica en la Universidad de Alcalá en 1522» (p. 23).

Otro aspecto -digno de mención- sería el «irenismo» del humanista, considerado en el capítulo 8 (p. 35-37). Éste le indujo a reprobar las hostilidades entre las naciones europeas ${ }^{17}$ en algunos escritos; uno de ellos sería sus Commentarii in xxii libros De civitate Dei: «quot viros caecidimus, quas villas incendimus, quos agros vastavimus, quas arces, oppida, urbes, evertimus; ac gloriae prope hoc solum datum est plurimum cladis humano generi attulisse. Sed si hic incipiam querelam hanc, quando finis?» (Vivis. Comm.19, 13, b) ${ }^{18}$. Además, se incide en la nostalgia del erudito valenciano; este sentimiento se aprecia en el fragmento 12, que permite al profesor Francesc concluir su biografía con un Vives «consciente de que ya no regresaría a su tierra antes de fallecer» (p. 47). En definitiva, la publicación de Hernàndez i Dobon goza de suficiente información para hacer accesible tan insigne figura a cualquier persona que quiera comprender la vida y obra de Vives, promoviendo una lectura directa de sus principales tratados. 


\section{NOTAS}

1. Joannis Ludovici Vivis Valentini Opera Omnia, Distributa Et Ordinata In Argumentorum Classes Praecipuas A GREGORIO MAJANSIO, GENER. VALENT. [...], Valentiae Edetanorum, in officina Benedicti Monfort, Anno M.DCC.LXXXVII.

2. La edición latina de Mayans se puede consultar en la Biblioteca Valenciana Digital. Véase en este enlace la Ioannis Ludovici Vivis Vita: https://bivaldi.gva.es/va/catalogo_imagenes/ grupo.do?ocultarCabecera=S\&presentacion=pagina\&path=1000001\&posicion=41 (28/07/2020).

3. Carlos Noreña, Juan Luis Vives, La Haya, Martinus Nijhoff, 1970.

4. Valentín Moreno Gallego, La recepción hispana de Juan Luis Vives, Valencia, Conselleria de Cultura, Educació i Esport, 2006.

5. Información comunicada por el autor en un correo electrónico con fecha de 27 de julio de 2020 .

6. Angel Gómez-Hortigüela Amillo, «La vida sine querella de Juan Luis Vives», eHumanista: Journal of Iberian Studies, 26 | 2014, 397-408.

7. José Peña González, Un español en Europa. Una aproximación a Juan Luis Vives, Madrid, Fundación Universitaria San Pablo ceu, 2003.

8. Se refiere al texto 4 de la selección (p. 65-66).

9. Se alude al texto 3 de este compendio (p. 63).

10. Vives consideraba esta ciudad «su patria como si fuese Valencia»; así lo expresó en el prólogo de su Socorro de los pobres : «et ut sit alienum aliquid, ego vero sic in civitatem hanc afficior, ut in Valentiam meam; nec aliter hanc nomino quam patriam» (Mayans, 1790: t. iv, 420).

11. Páginas pertenecientes al capítulo 9.

12. Ismael Roca Meliá, Colección Luis Vives \{12 vols.\}, Valencia, Ajuntament de València, 1992.

13. José Jiménez Delgado, Epistolario, Madrid, Editora Nacional, 1978.

14. Lorenzo Riber, Obras completas \{2 vols.\}, Madrid, M. Aguilar, 1947.

15. Revista de la Universitat de València creada en 2016 por la Associació d'Amics de Lluís Vives: https://ojs.uv.es/index.php/vivesiana/index (31/07/2020).

16. José Antonio Escudero López, «Juan Luis Vives y la inquisición», Revista de la Inquisición, 13 | 2009, 11-24.

17. Vives sólo aplicaba la paz a la cristiandad. Prueba de ello sería su inflexible Quam misera esset vita christianorum sub turca (Brujas, 1529).

18. En la Biblioteca Digital Valenciana, se encuentra la Editio Parisina de 1531 completamente digitalizada. Con todo, el pasaje citado en esta reseña aparece censurado: https://bivaldi.gva.es/ catalogo_imagenes/grupo.do?posicion=11\&path=1000118\&ocultarCabecera=S\&presentacion =pagina (02/08/2020). Por este motivo, se ha tomado de la Editio Basileensis de 1522, que se puede consultar en el fondo online de la Biblioteca Estatal de Baviera: https:// reader.digitalesammlungen.de/de/fs1/object/display/bsb10148486_00018.html? rotate $=360 \&$ zoom $=0.8000000000000003(02 / 08 / 2020)$. 


\section{AUTORES}

PEDRO FERNÁNDEZ REQUENA

Universidad de Valencia 